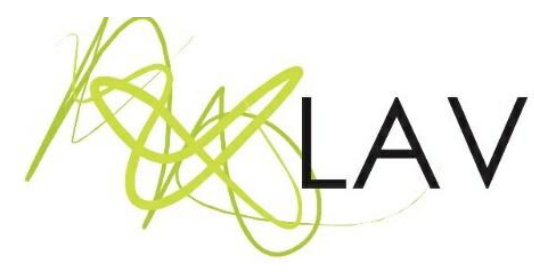

\title{
O que as (pessoas que ensinam com) imagens realmente querem?
}

\author{
Realmente ¿qué quieren (las personas que enseñan con) las imágenes?
}

\author{
Juan Sebastián Ospina Álvarezi \\ Universidade Paulista - UNIP; Universidade Federal de Goiás - UFG
}

Nayara Joyse Silva Montelesii

Universidade Federal de Goiás - UFG

\begin{abstract}
Resumo
No presente artigo, expõe-se uma reflexão sobre as práticas educativas da cultura visual ou educação da cultura visual (DIAS, 2012) sob o questionamento "o que as (pessoas que ensinam com) imagens realmente querem?", adaptação da pergunta de Mitchell (2017): o que as imagens realmente querem? Compreende-se que as imagens, quando utilizadas nas práticas educativas, tornam-se tanto recursos pedagógicos quanto ferramentas metodológicas cujos caminhos e possibilidades se desdobram à medida que os sujeitos se envolvem na produção de conhecimento. Assim, esta discussão pauta-se em compreender o que realmente desejam as pessoas que realizam trabalhos pedagógicos com imagens, pensando as imagens a partir do viés dos estudos da cultura visual.
\end{abstract}

Palavras-chave: educação da cultura visual, imagens, práticas educativas.

\begin{abstract}
This article reflects on critical pedagogy practices related to forms of visual culture education (DIAS, 2012) starting from a question, "What do (people who teach with) pictures want?" adapted from a previous one posed by Mitchell (2017), "What do pictures really want?" The discussion considers that when incorporated into pedagogical practices, images serve not only as a pedagogical resource but also as methodological tools that unfold other paths and possibilities for subjects to engage in knowledge production. Grounded in the field of visual culture studies, this investigation finally seeks to understand what someone really want when they approach images from a pedagogical perspective.
\end{abstract}

Keywords: visual culture education, images, pedagogy practices.

Enviado em: 24/02/20 - Aprovado em: 12/08/20

\section{Introdução}

Os estudos da cultura visual abriram um enorme leque de possibilidades para discutir questões relativas às imagens e suas influências nas relações culturais dos sujeitos. 
Com o estabelecimento deste campo, nas últimas décadas do século passado, foram introduzidos novos conceitos sobre os contextos de produção e consumo dos artefatos visuais. Diante das oportunidades e diversidade no uso de imagens, deparamo-nos com uma virada no ensino das artes visuais que instiga a pensar, entre muitas outras questões, em metodologias de ensino com uma perspectiva plural para trabalhar e explorar a cultura visual.

Neste texto, optamos por levantar assuntos relacionados com a perspectiva dos processos pedagógicos por meio de imagens. Além disso, este artigo nos serviu como pretexto para refletir sobre questões emergentes que nos causam certo desconforto. Assim, nossas reflexões nasceram de várias inquietações sobre o modo como o ensino de arte é trabalhado, no qual se dota a imagem de vida e poder e, muitas vezes, deixa-se de perceber a potência, no processo de mediação, derivada do educador ou educadora e do olhar do educando e educanda ao refletir sobre e desde as imagens.

Quando nos voltamos para o ensino de artes visuais estamos revisitando nossos processos, (re)avaliando nossos fazeres e escolhas como docentes ao traçar outras possibilidades pedagógicas no campo de ensino de arte e cultura visual a partir das imagens. A complexidade desse exercício está para além de pensar o poder das imagens, e sim em entender outras dinâmicas e agenciamentos pedagógicos que envolvem a produção imagética em sua diversidade de técnicas e estéticas, bem como a discussão de assuntos com ênfase no cultural e no social. Nesse sentido, este trabalho se constitui como um esforço para pensar "as realidades, os contextos e as subjetividades pelas quais os estudantes vêem, visualizam e constroem seus universos" (DIAS, 2012, p. 58).

Este artigo, da mesma forma que o texto de William John Thomas Mitchell (2017), nasce como um exercício de pensamento em vez de um tratado para obter respostas, neste caso sobre o que as pessoas que ensinam com imagens realmente querem. Refletimos com base em nossos desejos, anseios, inquietações e insatisfações diante de um quadro de narrativas educacionais que se encerram na idolatria às imagens e, ainda, de um conjunto imagético legitimado pelo campo da arte de matriz eurocêntrica e que, poucas vezes, abre espaços para outros contextos e outras produções visuais.

Dessa forma, a força motriz para o desenvolvimento deste texto foi pensarmos os processos de mediação e, mais uma vez, salientar a importância de uma educação mediante as contribuições dos estudos da cultura visual que abordam não somente os signos, mas também as (inter)ações. Não temos o intuito de reproduzir os discursos que corriqueiramente legitimam que as imagens por si só educam, mas corroborar com metodologias de ensino no campo da arte, ou seja, como essas imagens podem educar se 
é que são elas que educam. Ressaltamos que estamos cientes de que essa discussão é densa, complexa e sem possibilidade de ser findada em um único artigo.

Por meio deste escrito, almejamos refletir a partir da diversidade imagética e pensar outras possibilidades pedagógicas atravessadas de sentidos e saberes cotidianos. Desse modo, nossa intenção é discutir um ensino de artes com base em imagens, legitimadas ou não pelo campo da arte, pois compreendemos que há um potencial educativo nas visualidades cotidianas disseminadas em revistas, na rede mundial de computadores, na televisão, em outdoors, panfletos, imagens realizadas pelas e pelos alunos e/ou docentes etc. Esta escolha se configura como um desafio e abre portas para o surgimento de discursos pautados em experiências, levando-nos a refletir sobre o modo como percebemos e visualizamos o mundo enquanto sujeitos e docentes. $E$, tal pensamento, vai ao encontro do que ressalta Paulo Freire (1989) ao destacar que "a leitura de mundo precede a leitura da palavra" (FREIRE, 1989, p. 11), pois já éramos sujeitos atravessados por imagens, visualidades e discursos antes de passar por processos de formação e prática docente.

Apoiamo-nos na abordagem de Freire (1989), mas também optamos por olhar para nossas experiências e outras visualidades para percebermos a aprendizagem correlacionando os conteúdos formais e o dia a dia. Neste caso, explorar pontos que evidenciam a construção de conhecimento com ênfase em uma educação nas margens, e ao mesmo tempo, fronteiriça. Desse modo, realçamos outras possibilidades de aprender ao ensinar. Todavia, é importante frisarmos que a construção deste artigo se dá não somente por meio da busca de uma única resposta ao questionamento que lançamos, mas das múltiplas possibilidades de interpretação da arte e da cultura visual.

Assim, diante da amplitude da temática, entrelaçamos nossos diálogos norteados pelos seguintes questionamentos: i) quando falamos ou pensamos que as imagens educam, de quais imagens estamos falando? ii) Quais caminhos pensamos quando falamos em educar desde as imagens? iii) O que compreendemos como educação para a cultura visual?

Para abraçar esses questionamentos, propomos, em um primeiro momento, focalizar o questionamento 'quais imagens educam?'; em seguida, expressar perspectivas educacionais, caminhos e possibilidades de mediação, tendo como referência experiências pedagógicas. 


\section{Quais imagens 'educam'?}

Nas palavras de Rancière (2017), o mundo das imagens que Mitchell (2017) evoca não é um mundo de discursos generalizados, pelo contrário, "é um tecido vivo que substitui, como as imagens de Deleuze, uma história natural" (RANCIÈRE, 2017, p. 194). Em outras palavras, a jogada de Mitchell tem a ver com o próprio deslocamento que os estudos da cultura visual fazem quando, além da importância destacada do objeto-obraimagem, outorgam especial importância ao lugar do ou da intérprete e da ou do produtor.

Em épocas de grandes regimes sociopolíticos e, também, regimes de visualidades hegemônicas ao serviço dos grandes centros de poder, subverter é um convite, pelo menos no referido à rigidez das escolhas pedagógicas e visuais e do papel de intervenção nelas e a partir delas. As imagens podem se tornar subversivas no momento que convidam a deslocar o olhar, não só por elas, superfícies pigmentadas ou projetadas, mas na relação imagens e visualidades.

A escolha monopolizada por parte do ou da docente das imagens que irão ser usadas em um projeto de ensino e aprendizagem e, ainda, dos sentidos que elas trazem, significa cercear as possibilidades de construção de conhecimento no campo da cultura visual e da vida social das imagens. Seguindo a provocação de Mitchell (2017), as imagens pedem atenção, algumas mais que outras; 'elas' que, ao mesmo tempo são experiências formalizadas de produção e recepção, desejam frequentar salas de aula e outros cantos onde aprendemos e ensinamos e, portanto, devemos, como tarefa, pensar o porquê haveria que recusar o ingresso delas.

As imagens legitimadas pela história da arte eurocêntrica continuam sendo, dentro do contexto escolar, uma das fontes básicas para pensar possibilidades pedagógicas no ensino das artes visuais. Elas fazem parte da cultura visual com a qual a maioria dos estudantes se debruça nas suas aulas. Contudo, hoje os produtores de cultura visual não são somente aquelas pessoas chanceladas como artistas pelos circuitos da arte e nem aqueles que ocupam os espaços da arte como galerias, centros culturais e museus, mas principalmente essas mesmas pessoas que percorrem salas e espaços de interação, aprendendo e ensinando.

As imagens estão carregadas de sentidos sobre a vida cultural dos contextos, são recursos pedagógicos usados para desvendar e deflagrar análises críticas sobre sua gênese, não só no sentido de contestá-las, quando necessário, mas principalmente no intuito de compreender, de forma conectada, o que essas imagens podiam representar no 
tempo em que foram produzidas e, além disso, o que elas têm para nos dizer nos dias de hoje, ou melhor ainda, o que podemos dizer sobre elas e com elas.

Vale a pena retomar a pergunta que conduz esta reflexão e nos questionar, compreendendo que não só os e as docentes são as pessoas que trabalham com imagens, mas também as e os estudantes, o que nos move a participar de um processo onde a linguagem visual tece os fios que sustentam as redes discursivas surgidas dentro de uma aula, um encontro, um bate-papo e qualquer espaço que aproveitemos para aprender e ensinar?

Mergulhando em assuntos já tratados acima, sobre a produção de cultura visual, é muito importante observarmos o que realmente querem as e os estudantes quando levam imagens para sala de aula e, ainda, o que querem quando se dispõem a falar sobre elas. Centrar a atenção nos sujeitos que coletam esses artefatos nos leva, consequentemente, a escavar assuntos como os fatores motivacionais para realizar determinadas escolhas, origem material das imagens, relação com o cotidiano das pessoas e as próprias conexões que seu coletor ou coletora lança nessa maré de redes que, ora está cheia de 'viandas visuais' para roer e explorar, ora menos fornida, mas nunca limpa a tal ponto de não propiciar motivos para nos reunir e desemaranhar os fios que novamente lançaremos para caçar outros artefatos que podem ser servidos, mas que cada qual tempera de acordo com seu gosto.

\section{Perspectivas educacionais}

As diretrizes educacionais atuais, em constante processo de reformulação, têm feito com que diversos educadores e educadoras se voltem novamente para discussões pautadas no ensino de artes visuais, bem como reflitam sobre os repertórios imagéticos que estão sendo trabalhados em sala de aula. Como docentes, nossa preocupação voltase para atender as necessidades educacionais dos sujeitos em formação, possibilitando, por meio de atividades e ações pedagógicas, que os alunos reflitam, de modo crítico, sobre a vida por meio da arte e da arte no meio da vida. Além disso, alguns fazeres educacionais têm como perspectiva a promoção de diálogos entre os sujeitos envolvidos no processo (discentes, docentes e comunidade escolar), a construção de laços de afeto e respeito, o desenvolvimento integral voltado não só para o trabalho, mas também, e fundamentalmente, para a vida. 
Diante disso, pensar as ações pedagógicas tocando em temáticas que atravessam o cotidiano e ampliando o leque de imagens é promover o que preconiza a Lei de Diretrizes e Bases 9.394/96. O Artigo 1 dispõe que

a educação abrange os processos formativos que se desenvolvem na vida familiar, na convivência humana, no trabalho, nas instituições de ensino e pesquisa, nos movimentos sociais e organizações da sociedade civil e nas manifestações culturais (BRASIL, 1996).

Enquanto educadores, gostaríamos de observar que não abrimos mão das imagens legitimadas pelo campo da arte, daquelas que foram chanceladas como arte, mas ampliamos nossas escolhas para outros repertórios que também falam das subjetividades dos e das 'jovens produtores de cultura visual'. Esse termo, alcunhado por Imanol Aguirre (2014), é reflexo do cenário que vivenciamos e que ganha força com as redes sociais nas quais os e as jovens têm, cada vez mais, exposto suas vidas e seus interesses em formato visual. Assim, essas imagens se constituem como artefatos que adquirem sentidos em meio à veiculação em redes sociais como Instagram, Facebook, Twitter e Tik Tok. Nesse seguimento, por que não trabalhar tais imagens em sala de aula e pensar uma relação com aquelas denominadas de arte? De quem ou do que uma imagem fala senão de nós mesmos e/ou dos contextos vivenciados cotidianamente?

Estabelecer uma relação com o cotidiano desses e dessas jovens produtoras de cultura visual pode ser considerada uma das aberturas para aproximar docentes e discentes. Não se pode negligenciar a 'experiência de mundo' dos e das educandas e os modos como se percebem em meio aos conflitos vivenciados e à necessidade de afirmação de suas identidades plurais. Diante disso, Campos (2010), ao destacar o modo como os e as jovens experimentam as visualidades, observa que:

Não podemos [...] ignorar a forma como as culturas juvenis têm utilizado a visualidade como território privilegiado de diálogo, campo de combate ideológico e simbólico, de afirmação identitária, de jogo e prazer, aproveitando aparelhos especializados como o corpo [...], os adornos e o vestuário, o consumo (de televisão, cinema, música, etc.) e a criação de objetos culturais diversificados (graffiti, stickers, tatuagens, fanzines, weblogs, fotologs, etc.). A visualidade é, assim, cada vez mais, uma arena de prospecção criativa, de afinação de competências sociais, culturais e simbólicas que, tantas vezes, é desconhecida ou censurada pelo universo adulto (CAMPOS, 2010, p. 120).

É, sem dúvida, a partir desse território de diálogos de repertórios que surgem as subjetividades dos sujeitos e que nos propomos a pensar uma proposta pedagógica que reflita os trânsitos, as trocas e os compartilhamentos de imagens e saberes. 
Lembramos que o cotidiano apresenta uma série de temáticas que podem ser trabalhadas em meio ao próprio currículo. Portanto, pensar o que querem as imagens é provocar os sujeitos para que reflitam as simbologias que elas apresentam, tendo sempre como base suas experiências. Nesse sentido, as noções de troca e de compartilhamento perpassam pela compreensão de que nem sempre cabe ao docente realizar as escolhas do que pode ser visto em sala de aula.

Diante do exposto entendemos ser necessário pensar não somente o que querem as imagens, mas como os e as docentes em meio aos seus contextos distintos podem optar por metodologias cujas imagens sejam deflagradoras de conteúdos significativos e que esses conjuntos de visualidades e artefatos visuais sejam frutos da cotidianidade que grita de modo latente nos discursos em sala de aula. Assim, caro leitor e cara leitora, quais seriam as imagens que você usaria? Como você estabeleceria conexões com o lastro da história e da memória? Como conectaria o currículo às temáticas do cotidiano?

Estabelecemos seis pontos, não fixos, para pensar metodologias de pesquisas visuais. Desde já esclarecemos que não há uma ordem específica para pensar a pesquisa com e sobre imagens do cotidiano como suporte para o ensino da arte a partir da cultura visual, sejam esses artefatos legitimados ou não pelo campo da arte, conforme é possível observar no gráfico 1. Os pontos são: IMAGEM/EIXO TEMÁTICO - PESQUISA INTERPRETAÇÃO - DIÁLOGOS - PRODUÇÃO - REFLEXÃO.

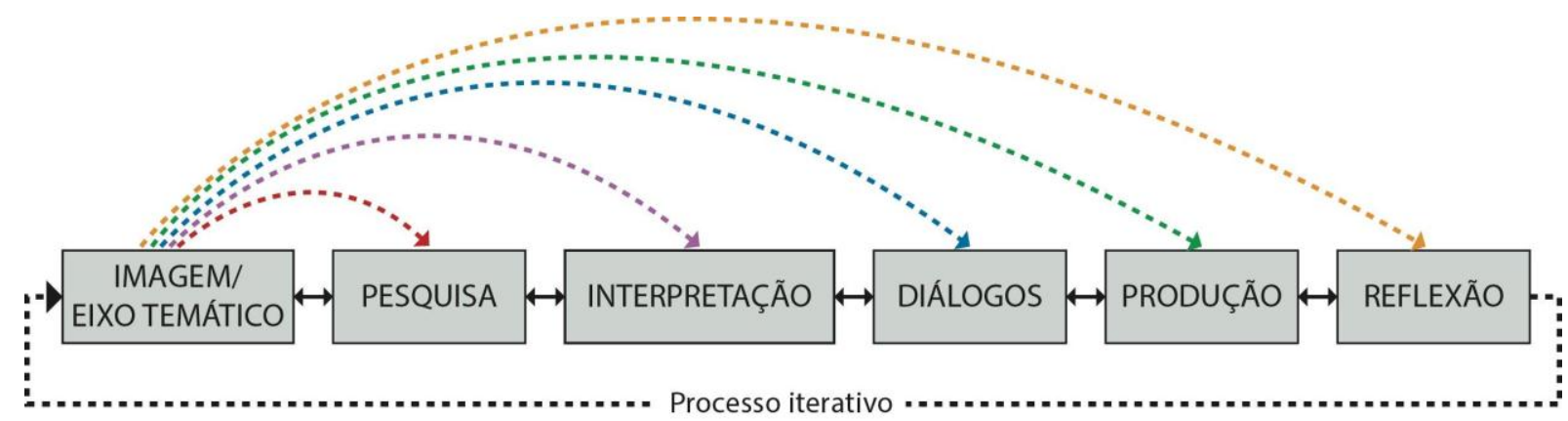

Gráfico 1: Operacionalização didática da proposta Fonte: Autoria própria (2020)

IMAGEM/EIXO TEMÁTICO - compreendemos que as imagens estão imbuídas de conteúdos e que eles estão relacionados ao currículo; assim, as imagens são eixos temáticos que devem ser selecionados como base de discussão, o que contribui para ampliação e construção do saber em sala de aula, tanto da própria arte como da vida. 
PESQUISA - ponto essencial para estimular as e os educandos a se perceberem como parte do processo de construção da aula. As imagens, como se fossem um hiperlink, devem estar associadas às imagens anteriores que se conectam à IMAGEM -EIXO TEMÁTICO. Assim, a busca pode ser por imagens/visualidade e artefatos culturais que se conectem aos discursos e saberes que atravessam a noção de tempo: passado, presente e futuro.

INTERPRETAÇÃO - momento de retomar a discussão com ênfase. A priori, os discursos têm por ordem contextualizar e levantar novos questionamentos para promover reflexão, sem perder de vista a noção de memória, histórias. Faz-se necessário, com pauta nas imagens e com base na discussão, levar a ou o educando a pensar: quais os fatores motivacionais para a escolha dessas imagens? De que modo elas se conectam? Quais técnicas foram usadas para sua produção? Quais canais foram usados para sua divulgação? O que elas fazem lembrar - uma experiência pessoal, familiar, escolar, etc.?

DIÁLOGOS - envolvem a construção de mapas e trocas mentais e conceituais para compreender as relações por meio de uso de signos e palavras-chave provenientes dos discursos gerados. Nesse sentido, a IMAGEM/EIXO TEMÁTICO nos leva a pensar a partir desse ponto as conexões/diálogos tecidos nos quais se produz um mapa que estimule novas produções de sentidos. A escolha das palavras e imagens deve ser realizada coletivamente e sempre à procura de uma configuração orgânica dos saberes.

PRODUÇÃO - após uma profunda reflexão, é importante pensar novas produções que ampliem a discussão. Nesse sentido, nosso interesse é que a ou o educando possa voltar-se para criação de contra-narrativas que evidenciam que o aluno se apropriou do conteúdo/imagens para gerar novas produções com uso de materiais e tecnologias distintas. Compreendemos a importância da criticidade para criação de imagens e para pensar as problemáticas cotidianas. $\mathrm{O}$ artefato e/ou temática que vira força motriz para produção de novas imagens pode ser motivado pelo mapa construído, o qual permite uma visualização panorâmica dos diálogos.

REFLEXÃO - o momento de reflexão é, de certo modo, uma pausa para retomar a discussão, o mapa e as produções, assim como para estabelecer novas conexões, com o intuito de fazer amarrações na discussão realizada. É necessário observar que a imagem é o elo de conexão entre conteúdo e novas visualidades. Nessa fase, os sujeitos mediadores podem aproveitar para realizar experiências avaliativas, autoavaliativas e realizar ajustes na empreitada de reconhecer o que eles realmente querem quando escolhem ou produzem imagens. 


\section{Alguns direcionamentos para pensar práticas de ensino}

Mitchell (2017) destaca o poder que as imagens têm para afetar as emoções e os comportamentos humanos. Nós, neste texto, defendemos que o poder dos processos de ensino com e através de artefatos das mais diversas culturas visuais têm o poder de afetar a construção de conhecimento, assim como a relação entre as visualidades e o pensamento crítico sobre elas e sobre outros enunciados que fundamentam as relações de poder e saber.

Contudo, não se trata somente de discorrer sobre a cultura visual dos sujeitos envolvidos nos processos acadêmicos, mas sim de trabalhar com os artefatos das culturas visuais dos educandos. Essa virada nos objetos deflagradores das práticas de ensino sobre e com cultura visual permite trabalhar com projetos que, na maioria das vezes, têm alcances metodológicos, políticos e estratégicos (PORRES PLA, 2015). Analisando essas mudanças desde a perspectiva metodológica, elas possibilitam maneiras diferenciadas de trabalhar na sala de aula com imagens e visualidades; no âmbito do político se dinamizam por tratar com os posicionamentos das pessoas contempladas; e, podem ser observadas como um projeto estratégico, porque abrem vias de fortalecimento das práticas pedagógicas.

Mitchell (2017) também propõe, a modo de provocação, deslocar o desejo interpretativo das imagens pelo desejo das próprias imagens. Nesse sentido, poderíamos pensar em um deslocamento do desejo das pessoas que trabalham com ensino para as artes para um desejo da educação da cultura visual.

Nas palavras de Sergio Martínez Luna (2017), as imagens participam da construção de conhecimento de valores, configurando os imaginários e os processos identitários que mediam as trocas intersubjetivas. Ainda, o próprio autor, quando se pergunta, seguindo também o questionamento de Mitchell - o que realmente querem as imagens? -, lembra que essa pergunta "não elimina a interpretação dos signos, mas desloca tanto ao sujeito como ao objeto de interpretação" (MARTÍNEZ LUNA, 2017, p. 115, tradução livre). Esse deslocamento estaria dado em dois sentidos: no primeiro, ao tratar as imagens como organismos vivos com capacidade de agência e, no segundo, ao estarem subalternizadas por sua relação direta com assuntos de diferença, mas com o papel de protagonista na vida cultural e nas visualidades dos cantos onde elas têm estado e por onde percorrem.

Trabalhar com imagens, em sala de aula, significa abrir caminhos por trilhas asfaltadas sobre campos porosos e afirmados por embates culturais, políticos, históricos e acadêmicos. Caminhar por esses sendeiros é se atentar pelas paisagens ao redor, algumas 
já conhecidas, mas outras que têm ficado para trás devido às ocultações programadas, daí que nós, pessoas que trabalhamos com imagens, queiramos que elas sejam vistas com todos os sentidos, principalmente levando em consideração os sentidos culturais, aqueles que não têm uma cor ou um tamanho dentro das superfícies, mas que ganham forma e peso nas relações suscitadas nas comunidades e espaços de ensino.

Se na visão de Mitchell as relações que as imagens estabelecem com sujeitos e coisas as tornam desejantes, deflagradoras de experiências sensíveis e afetivas, no caso deste artigo poderíamos falar, então, de uma docência de artes visuais desejante? Pois bem, trata-se de uma docência focada nos modos de vinculação entre os artefatos das diversas culturas visuais, as subjetividades das pessoas envolvidas nos processos de ensinar-aprender e os impactos do destrinchar os discursos visuais. Por fim, deixamos ao leitor o questionamento com o qual iniciamos este texto: o que as (pessoas que ensinam com) imagens realmente querem?

\section{Referências}

AGUIRRE, I. Entorno de aprendizagem entre jovens produtores de Cultura Visual: traços e características. In: MARTINS, R.; TOURINHO, I. (Orgs.) Pedagogias Culturais. Santa Maria: Editora UFSM, 2014, p. 247-274.

BRASIL, Lei de Diretrizes e B. Lei no 9.394/96, de 20 de dezembro de 1996. Brasília: Ministério de Educação - MEC, 1996.

CAMPOS, R. Juventude e visualidade no mundo contemporâneo: Uma reflexão em torno da imagem nas culturas juvenis. Sociologia, Problemas e Práticas, Oeiras, n. 63, p. 113-137, maio 2010.2 Disponível em: <http://www.scielo.mec.pt/scielo.php?script=sci_arttext\&pid=S087365292010000200007\&lng=pt\&nrm=iso >. Acesso em: 4 set. 2020.

DIAS, B. Arrastão: o cotidiano espetacular e práticas pedagógicas críticas. In: MARTINS, R.; TOURINHO, I. (Orgs.) Cultura das Imagens: desafios para a arte e para a educação. Santa Maria: Ed. UFSM, 2012, p. 55-73.

FREIRE, P. A importância do ato de ler: em três artigos que se completam. São Paulo: Autores Associados, 1989.

MARTÍNEZ LUNA, S. De mostrar el ver a la imagen que se muestra. El Ornitorrinco Tachado, Revista de artes visuales, [S.I.], n. 6, p. 107-117, nov. 2017. ISSN 2448-6949. Disponível em: <https://ornitorrincotachado.uaemex.mx/article/view/14418>. Acesso em: 4 set. 2020 .

MITCHELL, W. J. T. O que as imagens realmente querem? In: ALLOA, E. (Org.) Pensar a Imagem. Belo horizonte: Autêntica Editora, 2017, p. 165 -189.

PORRES PLA, A. 9 nubes: nueve anotaciones flotantes en torno a la investigación con jóvenes como productores de cultura visual en contextos educativos. In: AGUIRRE, I. 
(org.) + q knsmidrs d imgns: Mapeando evaluando la investigación sobre jóvenes productores de cultura visual. mor thN img cnsmrs: Mapping and Evaluating Research on Young People as Visual Culture Producers. Pamplona: Pamiela-Edarte (UPNA), 2015, p. 95113.

RANCIÈRE, J. As imagens querem realmente viver? In: ALLOA, E. (Org.) Pensar a imagem. Belo Horizonte: Autêntica Editora, 2017, p. 191-201.

' Doutor em Arte e Cultura Visual pela Universidade Federal de Goiás. Mestre em Design e Criação Interativa e bacharel em Design Visual pela Universidad de Caldas na Colômbia. Docente de Design Gráfico, Jornalismo e Marketing e Propaganda na Universidade Paulista - UNIP.

ii Mestra em Arte e Cultura Visual pela Universidade Federal de Goiás - UFG. Licenciada em Educação Artística com Habilitação em Artes Plásticas pela Universidade Federal do Maranhão - UFMA. Docente Substituta da Licenciatura em Artes Visuais da Faculdade de Artes Visuais - UFG.

Como citar esse artigo:

ÁLVAREZ, Juan Sebastián Ospina; MONTELES, Nayara Joyse Silva. O que as (pessoas que ensinam com) imagens realmente querem?. Revista Digital do LAV, Santa Maria: UFSM, v. 13, n. 3, p. 54-64, set./dez. 2020. 